\title{
Forest structure in the Far Western Terai of Nepal: Implications for management
}

\author{
S.K. Gautam ${ }^{1 *}$, Y.P. Pokharel ${ }^{1}$, K.R. Goutam ${ }^{1}$, S. Khanal ${ }^{1}$ and R.K. Giri ${ }^{1}$
}

\begin{abstract}
Forest inventory was conducted in 2009 in Kailali and Kanchanpur districts of the Far Western Development Region of Nepal. Altogether 282 circular plots were measured in 38 camp units equaling $0.02 \%$ sampling intensity. The average stocking (excluding regeneration) was 1201 number of stems per ha. The mean stem volume was $172 \mathrm{~m}^{3}$ $\mathrm{h}^{-1}$ and biomass was 186.6 tons $\mathrm{h}^{-1}$. Among the important tree species, Sal (Shorea robusta ) exhibited the highest biomass of $89.8 \mathrm{t} \mathrm{h}^{-1}$ and constituted $48.12 \%$ of the total stand biomass, followed by Asna (Terminalia tomentosa) $41.0 \mathrm{t} \mathrm{h}^{-1}$ or $21.00 \%$ of the total biomass. The biomass portions of other major species were Chirpine (Pinus roxburghii) 6.50\%; Haldu (Adina cordifolia) 3.23\%; and miscellaneous species $11.57 \%$. Total air-dry biomass, including stem, branches and leaves, of the two districts was calculated at 51.88 million tons, with Kailali having 37.26 million tons and Kanchanpur 14.68 million tons. The total carbon, after conversion, in forest trees of these two districts was 35.02 million tons. Change in mean stem volume, stocking and composition from earlier assessments underscores the need for appropriate silvicultural intervention.
\end{abstract}

Key words: Volume, biomass, carbon, Far Western Nepal, forest inventory

$\mathbf{T}$ imely forest inventory is imperative to understand the existing forest condition and maintain the long-term health and vitality of this resource. Quantitative information from forest inventory is of interest to a variety of stakeholders including forest managers, researchers, policy makers, and environmentalists. This inventory was carried in the winter of 2009 as a part of the Nationwide Inventory, a regular programme of the Department of Forest Research and Survey (DFRS). It aims to update the earlier information regarding the national forest status of Kailali and Kanchanpur Districts of Nepal (DFRS, 1999; DOF, 2005).

\section{Materials and methods}

\section{Study area}

The inventory was done in the forests of Kailali and Kanchanpur districts of the Far Western Terai region of Nepal (Fig 1). The Terai region experiences tropical to sub-tropical climate whereas there is temperate climate in the Churia hills. Maximum temperature reaches $46^{\circ}$ Celsius in summer and the minimum drops to $5^{0}$ Celsius in winter. Average annual precipitation is around $1550-1650 \mathrm{~mm}$ with the maximum precipitation during July-September and the average relative humidity is $74 \%$. The elevation ranges from 150 to $1520 \mathrm{~m}$ asl.

Kailali district covers $3284 \mathrm{~km}^{2}$ area and is located between $80^{\circ} 30^{\prime}-81^{\circ} 18^{\prime}$ E Longitude and $28^{\circ} 22^{\prime}$ $29^{\circ} 05$ N Latitude (DDC Kailali, 2002). Similarly, Kanchanpur district covers $1636.78 \mathrm{~km}^{2}$ area and extends from $28^{\circ} 32^{\prime}$ to $29^{\circ} 08^{\prime} \mathrm{N}$ Latitude and from $80^{\circ} 03^{\prime}$ to $80^{\circ} 33^{\prime}$ E Longitude (DDC Kanchanpur, 2002).

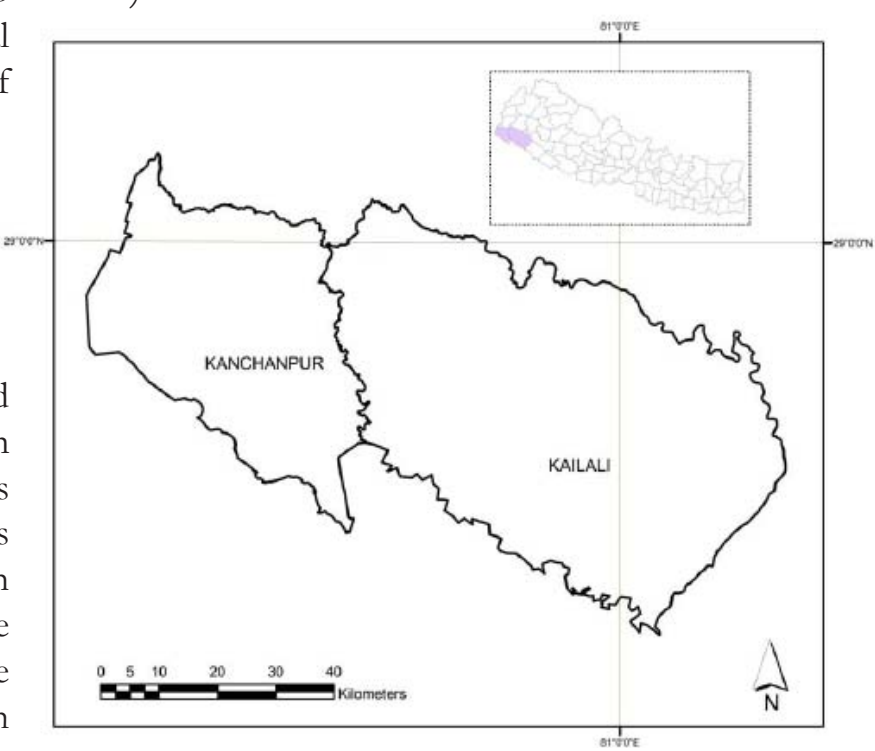

Fig 1: Map showing study districts

\footnotetext{
Department of Forest Research and Survey, Babarmahal, Kathmandu

Author for corrspondance: shreek_gautam@yahoo.com
} 


\section{Sampling design}

The topographic map sets $(1: 25000)$ covering the two study districts were acquired from the Department of Survey. These maps consist of grids one kilometre apart. Altogether 44 field sample units called 'camp unit' were laid to minimize time spent on travelling. Each camp unit consisted of a group of four clusters forming a square of $1 \mathrm{~km}$ by $1 \mathrm{~km}$. Each cluster comprised of two plots, one main and one sub-plot at a distance of $100 \mathrm{~m}$ north of the main plot (Fig 2). All the potential plots were laid out first on the Topo-sheet at a spacing of $2 \mathrm{~km}$ by $2 \mathrm{~km}$. Those plots having less than three corners in the forest land use in the Topo-sheet or located on the terrain having a hundred percent slope or located inside protected areas were excluded from the field inventory. Using a 0.01 percent sampling intensity, 44 sample units (referred as camp unit) were selected from a total of 440. Systematic sampling was used following a first sample drawn at random. GPS was used to locate the plot centres. Altogether 142 main plots were measured from 44 camp units.

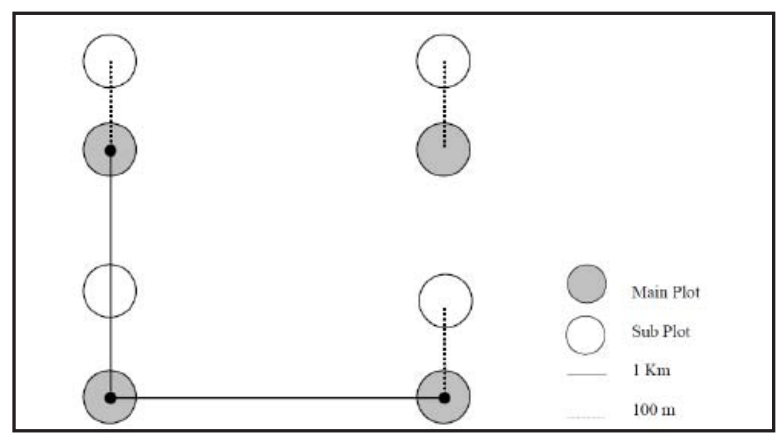

Fig 2: Camp unit design

\section{Measurement of trees}

Concentric circular plots were laid out ( Fig 3). All the seedlings $(<1.3 \mathrm{~m}$ height) of tree species falling within $2 \mathrm{~m}$ radius were counted and recorded, while all the stems ( $>1.3 \mathrm{~m}$ height) falling within the same radius were measured and recorded. Diameter of all the stems above $12 \mathrm{~cm}$ dbh and falling within $10 \mathrm{~m}$ radius; all the stems having $25 \mathrm{~cm}$ and above dbh and falling within $15 \mathrm{~m}$ radius; and all stems having $40 \mathrm{~cm}$ and above $\mathrm{dbh}$ and falling within $20 \mathrm{~m}$ radius were measured and recorded. Volume and biomass of the measured trees were calculated by using the equation $\ln V=a+b^{*} \ln (d)+c \ln (b)$. (Sharma and Pukkala, 1990a; Sharma and Pukkala, 1990b). Volume was converted into biomass by multiplying the wood densities (HMGN, 1989). Biomass was then converted into carbon with conversion factor as mentioned by Brown (1997) and Oli and Shrestha (2009).

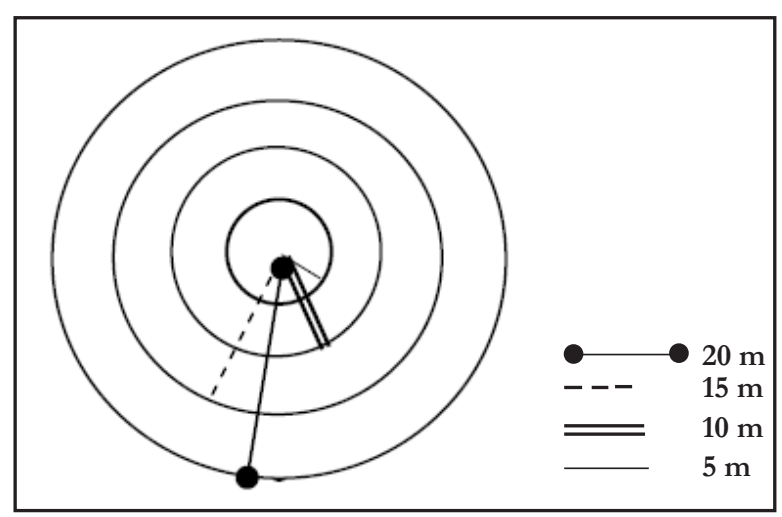

Fig 3: Layout of the concentric circular sample plot

\section{Results and discussion}

\section{Number of stems per hectare by diameter classes}

The distribution of the number of stems into different diameter size class is presented in Table 1. Principally in natural forest, there is always smaller proportion of big size trees than small ones, and this is also true in Kailali and Kanchanpur districts. There are on an average 1201 stems/ha. Earlier survey in 1990/91 recorded that the total number of stems per ha as 3843.7 in Kailali and 3194 in Kanchanpur district (DOF, 2005). It is important to note here that these results are not comparable because in the 1990 inventory above measurements were taken only from Terai belt of the district. On the other hand, this current 2009 inventory covered the entire area.

However, the overall observation including the field visits suggested that the number of stems/ha is decreasing. The findings also reveal that not only does the natural forest stem density condition seems to be poor but also that there is a domination of inferior species in the forest. This means the domination of miscellaneous species in lower diameter class (310 stems/ha) may lead to our future forest structure to be dominated by inferior species. Excluding miscellaneous (commercially less important trees found in mixed condition) species in the Terai, Sal (Shorea robusta) dominates other species. In each dbh class, Sal has the highest number of trees per ha. Similarly, Asna (Terminalia tomentosa) comes in as the second dominant species in terms of number of stems per ha.

\section{Volume}

The mean stem volume in Kailali and Kanchanpur districts was estimated to be $172 \mathrm{~m}^{3} /$ ha. This figure 
seems to be slightly less than the mean volume (178 $\mathrm{m}^{3} / \mathrm{ha}$ ) for Nepal and the mean stem volume of Far Western Development Region $\left(200 \mathrm{~m}^{3} / \mathrm{ha}\right)$ computed in the earlier inventory (DFRS, 1999). Of the total volume, Sal was found to contribute $45.2 \%$

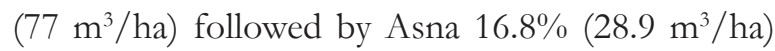
and miscellaneous species in Terai 15.6\% $\left(26.8 \mathrm{~m}^{3} /\right.$ ha) of the total stem volume. Likewise, Chirpine (Pinus roxburgbii) contributes $8.0 \%\left(13.8 \mathrm{~m}^{3} / \mathrm{ha}\right.$ ) of the total volume. Significant share of $17.8 \%(26.85$ $\mathrm{m}^{3} / \mathrm{ha}$ ) occupied by miscellaneous species in the Terai forest structures suggests the domination of low quality woods. We cannot present precise comparison regarding the species-wise stocking between this inventory and earlier inventory because the sampling frames for both the inventories were not identical. However, there is some indication of decrease in per hectare volume with respect to the 1990/1991 survey results which reported per ha volume $161.9 \mathrm{~m}^{3}$ in Kanchanpur district and 173.7 $\mathrm{m}^{3} /$ ha in Kailali district. Table 2 and Table 3 show the volume and basal area distribution of the sample trees in Kailali and Kanchanpur districts.

The mean basal area/ha was found to be $19.9 \mathrm{~m}^{2} /$ ha (Table 3). The most dominating tree species in terms of the basal area was Sal, constituting 38.2\% $\left(7.6 \mathrm{~m}^{2} / \mathrm{ha}\right)$ of the total basal area. The second biggest group was the miscellaneous species of the Terai with $20.6 \%\left(4.1 \mathrm{~m}^{2 /} \mathrm{ha}\right)$ share of the total basal area. The third dominant species was Asna covering $16.1 \%\left(3.2 \mathrm{~m}^{2} / \mathrm{ha}\right)$ of the total basal area.

\section{Biomass/carbon estimates}

The mean biomass was found to be 186.6 ton/ha. Among the important species, Sal exhibited highest biomass density ( 89.8 tons/ha) or $48 \%$ of the total stand biomass. It was followed by Asna with $22 \%$ (41.0 ton/ha). Other major species were Chirpine 6\%; Haldu (Adina cordifolia), 3\%; and miscellaneous species, $12 \%$ ( Table 4 ).

The total air dry biomass including stem, branches and leaves was found to be 51.88 million tons (Kailali: 37.26 and Kanchanpur: 14.68). Similarly, the total above and below ground carbon in the forests of both districts is estimated at 35.02 million tons (excluding grasses, regeneration, dead wood and soil). Root carbon was estimated as $35 \%$ of above ground carbon in forest trees.

\section{Conclusion and recommendation}

Density, volume, basal area and biomass are the key parameters for understanding the existing condition of the forest. This information is expected to be useful for further future monitoring of the forests in both districts. On the other hand, the information acquired from this inventory is expected to be useful for management planning of the forest resources in the two districts until the next inventory is conducted in the near future. Significant proportion $(17.8 \%)$ of the volume occupied by the miscellaneous species suggests that the Terai forest structures are being dominated by low quality trees. This result has important implication for the management of natural forest of this region. If we are going to focus on commercial timber species of high value, management must focus on promoting or providing a conducive environment for highly desirable species. This means removal of unwanted or less desirable species. Controlled burning and opening for light and other silvicultural treatment could be crucial for the management and improvement of the natural stands in both the districts.

One of the limitations of this inventory was the exclusion of protected areas as was done in the past, thus the mean estimates do not properly represent the protected areas. The concentric circular plot design is very convenient and appropriate for the terrain in Nepal. Regarding the accessibility, the Terai is more accessible with vehicles reaching most of the plots. But the real challenge is the terrain of Churia hills with steep slope and fragile surface to the north of the Terai.

Considering the use of equipment, the hand held GPS did not function well and there were the usual problems relating to linear tapes, slope correction, and movement between the plots within clusters. In the context of the ongoing Forest Resource Assessment Project, the demanding nature of the forest resource assessment in the hills and mountains need to be considered. The prospect of the project seems to be promising as it has planned to use laser equipment for distance measurement, latest GPS devices, and detailed and illustrated field manual. It also includes protected areas for inventory and plans to provide proper training to the crew members. 


\section{References}

Brown, S. 1997. Estimation Biomass and Biomass Change of Tropical Forest: A Primer: FAO Forestry Paper 134. Food and Agriculture Organization of the United Nations, Rome, Italy. 81-90.

DDC. Kailali. 2002. District Profile of Kailali, District, Development Committee (Nepali Version), Kailali, Nepal.

DDC. Kanchanpur. 2059. District Periodic Plan of Kanchanpur Part I and II. District Development Committee, Kanchanpur, Nepal.

DFRS. 1999. Forest Resources of Nepal (19871998). Department of Forest Research and Survey, Publication No. 74, Kathmandu, Nepal.

DOF. 2005. Forest Cover Change Analysis of the Terai Districts (1990/91-2000/01). Department of Forests, Kathmandu, Nepal.
HMGN. 1989. Master Plan for the Forestry Sector, Nepal: Forest Resources Information and Status and Development Plan. MFSC. Kathmandu,Nepal.

Oli, B.N. and Shrestha, K. 2009. Carbon status in forest of Nepal an overview. Journal of Forests and Livelihood 8 (1): 62-66.

Sharma, E.R and Pukkala, T. 1990a. Volume Equations and Biomass Prediction of Forest Trees of Nepal. Ministry of Forests and Soil Conservation. Forest Survey and Statistics Division, Kathmandu, Nepal.

Sharma, E.R. and Pukkala, T. 1990b. Volume Tables for Forest Trees of Nepal. Ministry of Forests nd Soil Conservtion, Forest Survey and Statistics Division. Kathmandu, Nepal.

\section{Table 1: Number of stems/ha (Mean + SE)}

\begin{tabular}{|c|c|c|c|c|c|c|}
\hline \multirow[t]{2}{*}{ S.N } & \multirow[t]{2}{*}{ Species } & \multicolumn{5}{|c|}{ Number of Stems/ha } \\
\hline & & $0-10 \mathrm{~cm}$ & $10-20 \mathrm{~cm}$ & $20-30 \mathrm{~cm} \quad 30-40 \mathrm{~cm}$ & $40-50 \mathrm{~cm}$ & $>50 \mathrm{~cm}$ \\
\hline 1 & Asna (Terminalia tomentosa) & $182.5 \pm 33.5$ & $36.8 \pm 4.4$ & $15.6 \pm 1 \quad 3.9 \pm 0.6$ & $2.3 \pm 0.4$ & $4.3 \pm 0.5$ \\
\hline 2 & Boddhaero (Lagerstroemia parviflora) & $42.1 \pm 8.2$ & $16.6 \pm 2.1$ & $5.5 \pm 0.5$ & $0.8 \pm 0.2$ & $0.5 \pm 0.1$ \\
\hline 3 & Chirpine (Pinus roxburghii) & $2.7 \pm 1.9$ & $9.2 \pm 1$ & $1.5 \pm 0.7$ & $1.2 \pm 0.4$ & $2.2 \pm 0.3$ \\
\hline 4 & Dhauti (Anogeissus latifolia) & $10.3 \pm 5.2$ & $6.8 \pm 2.1$ & $2.0 \pm 0.6$ & $0.2 \pm 0.1$ & $0.2 \pm 0.1$ \\
\hline 5 & Haldu (Adina cordifolia) & $3.1 \pm 1.3$ & $3.3 \pm 0.6)$ & $2.2 \pm 0.3$ & $0.2 \pm 0.1)$ & $1.1 \pm 0.2$ \\
\hline 6 & Jamun (Eugenia jambolana) & $12.6 \pm 8.3$ & $7.5 \pm 1.4)$ & $3.5 \pm 0.7$ & $0.5 \pm 0.1)$ & $0.4 \pm 0.1$ \\
\hline 7 & Misc. species in Hill & $20.6 \pm 9.1$ & $9.7 \pm 1.5)$ & $5.7 \pm 1.3$ & $0.4 \pm 0.1$ & $0.6 \pm 0.2$ \\
\hline 8 & Misc. species in Terai & $310.2 \pm 39.9$ & $81.2 \pm 5.4)$ & $28.4 \pm 1.6$ & $2.4 \pm 0.3$ & $2.9 \pm 0.4$ \\
\hline 9 & Quercus spp. & $1.8 \pm 8.1$ & $2.2 \pm 0.9)$ & $1.1 \pm 0.2$ & $0.1 \pm 0.1$ & 0.1 \\
\hline $10 \stackrel{9}{9}$ & Sal (Shorea robusta) & $184.7 \pm 30.9$ & $63.0 \pm 4.6)$ & $39.9 \pm 1.5 \quad 9.6 \pm 1.3$ & $7.5 \pm 0.8$ & $12.6 \pm 1.2$ \\
\hline 11 & Sindure (Mallotus philippinensis) & $159.2 \pm 30.1$ & $34.7 \pm 3.9)$ & $7.8 \pm 1.6) 0.9 \pm 0.3)$ & $0.2 \pm 0.1$ & $0.1 \pm 0.1$ \\
\hline & Total & $929.8 \pm 90.1$ & $152.9 \pm 11.7$ & $50.4 \pm 3.227 .1 \pm 1.9$ & $15.7 \pm 1$ & $25.1 \pm 1.3$ \\
\hline
\end{tabular}


Table 2: Volume/ha by species and dbh class (Mean + SE)

\begin{tabular}{|c|c|c|c|c|c|c|c|c|c|}
\hline \multirow[t]{2}{*}{ S.N. } & \multirow[t]{2}{*}{ Species } & \multicolumn{7}{|c|}{ Volume $\left(\mathrm{m}^{3} / \mathrm{ha}\right)$} & \multirow[b]{2}{*}{ In $\%$} \\
\hline & & $<10$ & $10-20$ & $20-30$ & $30-40$ & $40-50$ & $>\mathbf{5 0}$ & Total & \\
\hline 1 & Asna (Terminalia tomentosa) & $1.3 \pm 0.3$ & $1.8 \pm 0.4$ & $1.8 \pm 0.4$ & $3.1 \pm 0.5$ & $3.4 \pm 0.6$ & $17.5 \pm 2.0$ & $28.9 \pm 2.5$ & 16.8 \\
\hline 2 & Boddhaero (Lagerstroemia parviflora) & $0.3 \pm 0.1$ & $0.9 \pm 0.2$ & $0.8 \pm 0.2$ & $1 \pm 0.3$ & $1 \pm 0.2$ & $1.6 \pm 0.5$ & $5.6 \pm 0.8$ & 3.3 \\
\hline 3 & Chirpine (Pinus roxburgbii) & * & $0.2 \pm 0.1$ & $0.6 \pm 0.2$ & $1.5 \pm 0.7$ & $2.4 \pm 0.7$ & $9.1 \pm 2.3$ & $13.8 \pm 3.4$ & 8.0 \\
\hline 4 & Dhauti (Anogeissus latifolia) & $0.1 \pm 0$ & $0.4 \pm 0.2$ & $0.4 \pm 0.2$ & $0.2 \pm 0.1$ & $0.3 \pm 0.2$ & $0.7 \pm 0.4$ & $2.1 \pm 0.4$ & 1.2 \\
\hline 5 & Haldu (Adina cordifolia) & $*$ & $0.1 \pm 0.0$ & $0.1 \pm 0.1$ & $0.3 \pm 0.1$ & $0.2 \pm 0.1$ & $4.3 \pm 1.1$ & $5 \pm 1.2$ & 2.9 \\
\hline 6 & Jamun (Eugenia jambolana) & $*$ & $0.3 \pm 0.1$ & $0.4 \pm 0.2$ & $0.5 \pm 0.2$ & $0.5 \pm 0.2$ & $0.9 \pm 0.4$ & $2.6 \pm 0.7$ & 1.5 \\
\hline 7 & Misc. speices in Hill & $0.1 \pm 0$ & $0.4 \pm 0.1$ & $0.9 \pm 0.3$ & $0.6 \pm 0.2$ & $0.4 \pm 0.2$ & $1.4 \pm 0.7$ & $3.8 \pm 1.4$ & 2.2 \\
\hline 8 & Misc. species in Terai & $2 \pm 0.2$ & $3.6 \pm 0.3$ & $4.4 \pm 0.5$ & $4.4 \pm 0.6)$ & $2.9 \pm 0.4$ & $9.5 \pm 1.7$ & $26.8 \pm 2.3$ & 15.6 \\
\hline 9 & Quercus spp. & $*$ & $0.1 \pm 0.1$ & $0.2 \pm 0.1$ & $0.2 \pm 0.2$ & $0.1 \pm 0.1$ & $0.2 \pm 0.1$ & $0.8 \pm 0.5$ & 0.5 \\
\hline 10 & Sal (Shorea robusta) & $1.1 \pm 0.2$ & $2.4 \pm 0.4$ & $4.2 \pm 0.6$ & $8.3 \pm 1.2$ & $12 \pm 1.4$ & $49.8 \pm 5.3$ & $77.8 \pm 6.7$ & 45.2 \\
\hline \multirow[t]{2}{*}{11} & Sindure (Mallotus philippineusis) & $0.9 \pm 0.1$ & $1.7 \pm 0.2$ & $1.6 \pm 0.4$ & $0.5 \pm 0.2$ & $0.1 \pm 0.1$ & $0.1 \pm 0.1$ & $4.9 \pm 0.7$ & 2.8 \\
\hline & Total & 5.8 & 11.9 & 15.4 & 20.6 & 23.3 & 95.1 & 172.1 & 100 \\
\hline
\end{tabular}

* insignificant

Table 3: Distribution of basal area $\left(\mathrm{m}^{2}\right) /$ ha by dbh class $($ Mean $+\mathrm{SE})$

\begin{tabular}{|c|c|c|c|c|c|c|c|c|c|}
\hline \multirow[t]{2}{*}{ S.N. } & \multirow[t]{2}{*}{ Species } & \multicolumn{8}{|c|}{ Mean basal area $\left(\mathrm{m}^{2} / \mathrm{ha}\right)$} \\
\hline & & $<10$ & $10-20$ & $20-30$ & $30-40$ & $40-50$ & $>50$ & Total & In $\%$ \\
\hline 1 & Asna (Terminalia tomentosa) & $0.4 \pm 0.1$ & $0.3 \pm 0.1$ & $0.2 \pm 0.0$ & $0.4 \pm 0.1$ & $0.4 \pm 0.1$ & $1.6 \pm 0.2$ & $3.2 \pm 0.3$ & 16.1 \\
\hline 2 & Boddhaero (Lagerstroemia parviflora) & $0.1 \pm 0.1$ & $0.2 \pm 0.1$ & $0.1 \pm 0.0$ & $0.1 \pm 0.0$ & $0.1 \pm 0.0$ & $0.2 \pm 0.0$ & $0.8 \pm 0.1$ & 4.0 \\
\hline 3 & Chirpine (Pinus roxburgbii) & $*$ & $*$ & $0.1 \pm 0.0$ & $0.1 \pm 0.1$ & $0.2 \pm 0.1$ & $0.6 \pm 0.2$ & $1.1 \pm 0.3$ & 5.5 \\
\hline 4 & Dhauti (Anogeissus latifolia) & $*$ & $0.1 \pm 0$ & $0.1 \pm 0.0$ & * & $*$ & $0.1 \pm 0.0$ & $0.3 \pm 0.1$ & 1.5 \\
\hline 5 & Haldu (Adina cordifolia) & $*$ & $*$ & $*$ & * & * & $0.5 \pm 0.1$ & $0.6 \pm 0.1$ & 3.0 \\
\hline 6 & Jamun (Eugenia jambolana) & $*$ & $0.1 \pm 0.0$ & $0.1 \pm 0.0$ & $0.1 \pm 0.0$ & $0.1 \pm 0.0$ & $0.1 \pm 0.0$ & $0.4 \pm 0.1$ & 2.0 \\
\hline 7 & Misc. speices in Hill & $*$ & $0.1 \pm 0.0$ & $0.2 \pm 0.1$ & $0.1 \pm 0.0$ & $0.1 \pm 0.0$ & $0.2 \pm 0.1$ & $0.6 \pm 0.2$ & 3.0 \\
\hline 8 & Misc. species in Terai & $0.6 \pm 0.1$ & $0.8 \pm 0.1$ & $0.7 \pm 0.1$ & $0.6 \pm 0.1$ & $0.4 \pm 0.0$ & $1.0 \pm 0.2$ & $4.1 \pm 0.3$ & 20.6 \\
\hline 9 & Quercus spp. & $*$ & $*$ & $*$ & $*$ & $*$ & $*$ & $0.1 \pm 0.1$ & 0.5 \\
\hline 10 & Sal (Shorea robusta) & $0.3 \pm 0.1$ & $0.3 \pm 0.1$ & $0.5 \pm 0.1$ & $0.9 \pm 0.1$ & $1.2 \pm 0.0$ & $4.3 \pm 0.4$ & $7.6 \pm 0.6$ & 38.2 \\
\hline & Sindure (Mallotus philippineusis) & $0.3 \pm 0.0$ & $0.4 \pm 0.1$ & $0.3 \pm 0.1$ & $0.1 \pm 0.0$ & $*$ & $*$ & $1.1 \pm 0.1$ & 5.5 \\
\hline & Total & & & & & & & 19.9 & 100 \\
\hline
\end{tabular}

$*$ insignificant

Table 4: Biomass (metric tons/ha) with respect to dbh class (Mean $+\mathrm{SE}$ )

\begin{tabular}{|c|c|c|c|c|c|c|c|c|c|}
\hline \multirow[t]{2}{*}{ S.N. } & \multirow[t]{2}{*}{ Species } & \multicolumn{7}{|c|}{ Mean biomass (metric tons/ha) } & \multirow[b]{2}{*}{ In $\%$} \\
\hline & & $<10$ & $10-20$ & $20-30$ & $30-40$ & $40-50$ & $>50$ & Total & \\
\hline 1 & Asna (Terminalia tomentosa) & $1.9 \pm 0.4$ & $2.7 \pm 0.5$ & $2.6 \pm 0.5$ & $4.5 \pm 0.7$ & $5.1 \pm 0.9$ & $28.6 \pm 3.4$ & $45.4 \pm 4.0$ & 21.97 \\
\hline 2 & Boddhaero (Lagerstroemia parviflora) & $0.4 \pm 0.1$ & $1.2 \pm 0.2$ & $0.3 \pm 0.1$ & $1.3 \pm 0.3$ & $1.3 \pm 0.3$ & $2.3 \pm 0.7$ & $7.6 \pm 1.2$ & 3.27 \\
\hline 3 & Chirpine (Pinus roxburghii) & $*$ & $0.2 \pm 0.1$ & $0.5 \pm 0.3$ & $1.3 \pm 0.6$ & $2.0 \pm 0.6$ & $7.8 \pm 2.0$ & $11.8 \pm 2.9$ & 6.05 \\
\hline 4 & Dhauti (Anogeissus latifolia) & $0.1 \pm 0.1$ & $0.6 \pm 0.2$ & $0.6 \pm 0.2$ & $0.3 \pm 0.2$ & $0.4 \pm 0.2$ & $1.0 \pm 0.6$ & $3.0 \pm 1.0$ & 1.23 \\
\hline 5 & Haldu (Adina cordifolia) & $*$ & $0.1 \pm 0.0$ & $0.1 \pm 0.1$ & $0.3 \pm 0.1$ & $0.3 \pm 0.1$ & $5.0 \pm 1.3$ & $5.8 \pm 1.4$ & 3.05 \\
\hline 6 & Jamun (Eugenia jambolana) & * & $0.3 \pm 0.1$ & $0.5 \pm 0.2$ & $0.6 \pm 0.2$ & $0.7 \pm 0.2$ & $1.2 \pm 0.6$ & $3.4 \pm 0.8$ & 1.50 \\
\hline 7 & Misc. species in Hill & $0.1 \pm 0.1$ & $0.3 \pm 0.1$ & $0.9 \pm 0.3$ & $0.6 \pm 0.2$ & $0.4 \pm 0.2$ & $1.5 \pm 0.8$ & $3.9 \pm 1.5$ & 1.50 \\
\hline 8 & Misc. species in Terai & $2.0 \pm 0.2$ & $3.5 \pm 0.3$ & $4.4 \pm .4$ & $4.4 \pm 0.6$ & $3.0 \pm 0.4$ & $10.5 \pm 1.9$ & $27.8 \pm 2.4$ & 11.57 \\
\hline 9 & Quercus spp. & * & $0.1 \pm 0.1$ & $0.3 \pm 0.1$ & $0.3 \pm 0.1$ & $0.2 \pm 0.2$ & $0.2 \pm 0.2$ & $1.2 \pm 0.7$ & 0.42 \\
\hline 10 & Sal (Shorea robusta) & $1.1 \pm 0.1$ & $2.4 \pm 0.5$ & $4.6 \pm 0.7$ & $28.8 \pm 1.8$ & $14.9 \pm 1.7$ & $762.3 \pm 6.6$ & $95.3 \pm 8.3$ & 48.12 \\
\hline 11 & Sindure (Mallotus philippineusis) & $0.8 \pm 0.1$ & $1.7 \pm 0.2$ & $1.5 \pm 0.4$ & $0.5 \pm 0.1$ & 0.0 & $0.1 \pm 0.1$ & $4.7 \pm 0.7$ & 1.29 \\
\hline
\end{tabular}

* insignificant 